\title{
CIRCULATION OF THE AQUEOUS HUMOUR AND THE EXPERIMENTAL DETERMINATION OF ITS RATE OF FLOW*
}

\author{
BY \\ E. J. ROSS $\dagger$ \\ From the Institute of Ophthalmology, London
}

THE current concept of the physiology of the aqueous humour assumes a continuous circulation ("flow") of this fluid. From its ultimate source in the plasma, the aqueous humour is regarded as being formed by the diffusion of some of its constituents and the active transport (" secretion ") of others across cellular membranes situated principally in the ciliary body; the fluid so formed then circulates through the posterior and anterior chambers and leaves the eye, largely by drainage through Schlemm's canal, or through its homologue in lower animals.

The evidence for the presence of an aqueous circulation drawn from various sources has been summarized by Friedenwald and Pierce (1932a) and by Sugar (1942). Briefly, it is derived from clinical observations in cases of glaucoma and iris bombé, and from experimental studies, many of them made in the 19th century. Knies (1878) introduced dyes into the vitreous compartment and noted that they quickly found their way into the anterior chamber; similar observations were made by Gifford (1885), Ulbrich (1908), and Abelsdorff and Wessely (1909), among others. Leber $(1895 \mathrm{a}, \mathrm{b})$ first put forward the hypothesis of a through-and-through aqueous circulation, whereby the aqueous humour escaped from the anterior chamber by filtering through the trabeculum into Schlemm's canal and thence into the intrascleral venous plexus; this assumption was placed on a firmer foundation by the observation of Seidel $(1921,1922)$ that substances injected into the anterior chamber find their way into the episcleral vessels, and by the more recent discovery by Ascher (1942) of aqueous veins connecting Schlemm's canal and the limbal network with the conjunctival and episcleral veins.

Further support for the existence of a continuous flow of aqueous is derived from the consideration of equilibrium ratios (that is, the ratio of the concentration of a substance in the aqueous to its concentration in the plasmawater when a steady-state has been attained). Non-electrolytes entering the eye by diffusion should accumulate in the anterior chamber until their concentration in the aqueous humour equals that in the plasma-water. The existence of equilibrium values of less than unity is, however, well

* Received for publication October 5, 1951.

+ With a grant from the Alexander Pigott Wernher Memorial Trust Fund. 
documented; the concentration of urea in the aqueous humour is only 75 per cent of that in the plasma, and there can be no question of the utilization of this compound within the eye such as might be argued to be the explanation of the 15 per cent. deficit of glucose in the aqueous humour. Such a deficit is explicable on the hypothesis of a continuous circulation of aqueous humour and loss of the constituent by flow through Schlemm's canal. Kinsey and Grant (1942b) found that a rate of exit of 1.4 per cent. per minute agreed reasonably well with the curves they derived mathematically from experiments with eight different compounds in rabbits; this implied that all compounds left the anterior chamber at the same rate, a rate which represented the rate of flow.

\section{Methods of Measuring the Rate of Flow}

\section{(A) Direct Measurement}

From Hovius (1702) onwards, the early workers, who interested themselves in the rate at which the aqueous humour was " secreted", employed direct measurement, usually by cannulation of the anterior chamber and measurement of the quantity of fluid which emerged in a given time, or, using a manometer, by measuring the amount of fluid which had to be fed into the anterior chamber in order to keep the intra-ocular pressure constant. In many of these experiments, enucleated eyes were used. The disturbance to intra-ocular hydrodynamics which accompanies such methods precludes a physiological assessment, but, as they are of interest, some of the results so obtained have been set out in Table $I$.

A new method was introduced by Uribe y Troncoso (1909), who collected blood from the episcleral veins and estimated the extent to which it had been diluted by the aqueous humour draining into it. Friedenwald and Pierce (1932a) obstructed the normal outflow through Schlemm's canal with serum, and measured the rate of emergence of aqueous humour through a cannula inserted into the anterior chamber when the intra-ocular pressure was kept constant.

A more subtle approach was made by Bárány and Kinsey (1949), who took advantage of the rapid rate of clearance of certain substances by the kidneys after their introduction into the blood. These substances, the contrast media Rayopake and Diodrast, into which radio-active iodine had been introduced, and $p$-amino hippuric acid, were injected (separately) into rabbits, and the plasma concentration maintained high for 2 hours to enable diffusion into the eye to occur. The injection was then stopped and the plasma concentration fell off sharply; the first aqueous sample was removed when the plasma concentration had fallen below the aqueous concentration, and the second an hour later. When due allowance was made for the concentration of the test substance still remaining in the plasma, the value of the rate of exit $\left(k_{\text {out }}\right)$ could be calculated. Since the substances employed enter the aqueous very slowly, it was assumed that they would also diffuse out very slowly and would so leave the anterior chamber primarily by flow; the calculated value of the rate of exit would thus closely approximate to the value of the rate of flow $\left(k_{\text {flow }}\right)$.

Fluorescein was employed in a similar manner by Goldmann (1950), who measured its rate of disappearance from the anterior chamber following its intra- 
TABLE I

ESTIMATES OF THE RATE OF FLOW OF AQUEOUS HUMOUR OBTAINED BY DIRECT MEASUREMENT

\begin{tabular}{|c|c|c|c|}
\hline $\begin{array}{l}\text { Method of } \\
\text { Direct Measurement }\end{array}$ & Reference & Animal & $\begin{array}{l}\text { Rate of Flow } \\
\text { (cmm./min.) }\end{array}$ \\
\hline $\begin{array}{l}\text { Fluid emerging from anterior } \\
\text { chamber }\end{array}$ & $\begin{array}{l}\text { Jesner }(1880) \\
\text { Bentzen (1895) } \\
\text { Bellows and Chinn (1940) }\end{array}$ & $\begin{array}{l}\text { Rabbit } \\
\text { Rabbit } \\
\text { Dog }\end{array}$ & $\begin{array}{l}44 \\
5-6 \\
20\end{array}$ \\
\hline $\begin{array}{l}\text { Oil in anterior chamber } \\
\text { Cannula in vitreous }\end{array}$ & Leplat (1889) & Rabbit & 4 \\
\hline $\begin{array}{l}\text { Fluid required to keep intra- } \\
\text { ocular pressure constant }\end{array}$ & $\begin{array}{l}\text { Priestley Smith (1888) } \\
\text { Bentzen and Leber (1895) } \\
\text { Niesnamoff (1896) } \\
\text { Leber and Pilzecker (1906) } \\
\text { Henderson and Starling (1906) }\end{array}$ & \begin{tabular}{|l} 
Sheep (dead) \\
Human (dead) \\
Rabbit (dead) \\
Pig (dead) \\
Dog (dead) \\
Cat (dead) \\
Pig (dead) \\
Cat (dead)
\end{tabular} & $\begin{array}{l}26 \\
4-9 \\
7 \\
1 \\
7 \\
11 \\
24 \\
5-6 \\
10.8\end{array}$ \\
\hline $\begin{array}{l}\text { Outflow from anterior chamber } \\
\text { with Schlemm's canal blocked }\end{array}$ & $\begin{array}{l}\text { Friedenwald and Pierce } \\
\qquad(1932 a)\end{array}$ & Dog & 1 \\
\hline $\begin{array}{l}\text { Rate of formation of secondary } \\
\text { aqueous }\end{array}$ & Kronfeld and Lin (1936) & Human & 3 \\
\hline $\begin{array}{l}\text { Dilution of blood in episcleral } \\
\text { veins by admixture with } \\
\text { aqueous }\end{array}$ & Uribe y Troncoso (1909) & Rabbit & $2-3$ \\
\hline
\end{tabular}

venous injection in human subjects. Another method for the clinical measurement of the rate of flow in the human eye was devised by Grant (1950a), who found that in glaucoma there is not an excessive amount of aqueous formation but an increased resistance to its escape from the anterior chamber, an increased resistance which is detectable by Grant's " tonographic " method in early wide-angle primary glaucoma before the intra-ocular pressure becomes raised (Grant, 1950b).

A method, similar in principle to those of Bárány and Kinsey and of Goldmann, has been devised employing glucose and galactose. The blood level is raised by intravenous injection so that diffusion into the eye can occur. The blood glucose (galactose) level is then lowered by the intravenous injection of insulin, and the rate of disappearance of glucose (galactose) is determined by removing samples of aqueous humour at intervals of one hour. The objection may be raised in the case of glucose that some utilization occurs during the experiment so that the true rate of exit is slower than would appear from the rate of disappearance of glucose. This objection does not hold in the case of galactose, for this substance must be converted to glucose before it can be utilized, and the only known sites of such conversion are the liver, kidneys, and intestinal tract (Bollman, Mann, and Power, 1935). Table II (overleaf) summarizes the results obtained by various authors using this type of experimental method.

\section{Determination of Rates of Exit of Glucose and Galactose}

Method.-Rabbits weighing $2.0-2.2 \mathrm{~kg}$. were used under pentobarbitone sodium anaesthesia, except in two experiments in which general anaesthesia was not employed. 
TABLE II

RATE OF FLOW OF AQUEOUS HUMOUR DETERMINED BY THE RATE OF DISAPPEARANCE OF VARIOUS SUBSTANCES FROM THE ANTERIOR CHAMBER

\begin{tabular}{|c|c|c|c|}
\hline Reference & Animal & Substance & $\begin{array}{c}\text { Rate of Flow } \\
\text { (per cent. per min.) }\end{array}$ \\
\hline Bárány and Kinsey (1949) & Rabbit & $\begin{array}{c}p \text {-amino hippuric acid } \\
\text { rayopake } \\
\text { diodrast }\end{array}$ & $\begin{array}{l}1 \cdot 43 \\
1 \cdot 25 \\
1 \cdot 22\end{array}$ \\
\hline Goldmann (1950) $\quad \ldots \quad \ldots$ & Human & fluorescein & $1 \cdot \overline{1}$ \\
\hline Davson and Matchett (1951) & Rabbit & $p$-amino hippuric acid & 0.97 \\
\hline Bárány $(1951) \quad \ldots \quad \ldots$ & Chicken & $p$-amino hippuric acid & $1 \cdot 7-2 \cdot 0$ \\
\hline Present paper & Rabbit & $\begin{array}{l}\text { glucose } \\
\text { galactose }\end{array}$ & $\begin{array}{l}1 \cdot 58 \\
1 \cdot 03\end{array}$ \\
\hline
\end{tabular}

The blood level was raised by the intravenous injection of $20 \mathrm{ml} .5$ per cent. glucose or galactose. $30 \mathrm{~min}$. later a further $5 \mathrm{ml}$. were given intravenously. After one hour, 10 units of soluble insulin were given intravenously, and thereafter blood samples were taken at 10-min. intervals until the end of the experiment; the first aqueous sample was removed $45 \mathrm{~min}$. after giving the insulin, and the second sample $60 \mathrm{~min}$. after the first. Glucose was estimated by the method of Somogyi (1945), and galactose by the same method after the glucose had been removed by yeast fermentation.

Results.-The determinations of the rate of disappearance of glucose and galactose are presented in Table III. The mean rate of disappearance of glucose is $1.58 \times 10^{-2}$ min. $^{-1}$ (i.e. 1.58 per cent. per min.). This does not correspond to the rate of flow, since some glucose in the anterior chamber will be metabolized during the experiment, particularly by the lens, but since the amounts of glucose contributed to lens metabolism by the aqueous and vitreous respectively are

TABLE III

RATE OF DISAPPEARANCE OF GLUCOSE AND OF GALACTOSE FROM ANTERIOR CHAMBER OF

RABBITS CALCULATED AS

$$
k_{\text {inut }}=\frac{r}{t_{2}-t_{1}} \ln \left(\begin{array}{l}
C_{c_{1}}-r C_{t} \\
C_{c_{1}}-r C_{i}
\end{array}\right)
$$

\begin{tabular}{|c|c|}
\hline Glucose & Galactose \\
\hline $2 \cdot 22$ & $1 \cdot 16$ \\
\hline $1 \cdot 58$ & 0.94 \\
\hline $2 \cdot 62$ & 0.65 \\
\hline 1.48 & 0.95 \\
\hline$i \cdot 16$ & 1.49 \\
\hline $1 \cdot 63$ & $1 \cdot 45$ \\
\hline $0 \cdot 79$ & 0.77 \\
\hline - & $1 \cdot 01$ \\
\hline - & $0 \cdot 86$ \\
\hline Mean $1 \cdot 58 \pm 0 \cdot 25$ & Mean $1 \cdot 03 \pm 0 \cdot 11$ \\
\hline
\end{tabular}
not known, allowance for the amount of glucose lost by metabolism cannot be made.

The mean rate of disappearance of galactose was found to be $1.03 \times 10^{-2} \mathrm{~min}^{-1}$. This figure is low compared with the figure for glucose and will closely approximate to the true rate of flow, since there will be no loss by utilization and there is unlikely to be loss by diffusion across the iris.

\section{(B) Indirect MEASUREMENT}

The blood-aqueous barrier does not behave as an inert membrane but possesses a selective permeability. Each constituent of the aqueous humour crosses the barrier at a rate which is characteristic of that particular compound and is determined by its physico-chemical properties; in other words, each compound enters at its own individual rate. On the other hand, exit from the eye through Schlemm's canal is believed to occur by non-selective bulk flow; that is, all constituents leave at the same rate. In addition to this through- 
and-through circulation, there is also a diffusional exchange of water and probably of certain solutes between the aqueous humour and the vitreous body, the lens, and the cornea, and with the blood in the vessels of the iris. The concentration of a given constituent of the aqueous humour in equilibrium with its concentration in the plasma-water is the resultant of its rate of entry and its rate of exit. The relationship between these three variables, rate of entry $\left(k_{\text {in }}\right)$, rate of exit $\left(k_{\text {out }}\right)$, and equilibrium ratio $(r)$ can be derived from the fundamental permeability equation:

$$
\frac{d C_{a}}{d t}=k_{\text {in }} C_{p}-k_{\text {out }} C_{a}
$$

where the permeability constants $k_{\text {in }}$ and $k_{\text {out }}$ incorporate all the factors tending to transfer a given substance into, and out of, the aqueous humour; $C_{a}$ and $C_{p}$ represent the concentration of a given substance in the aqueous humour and plasma, respectively. At equilibrium:

since

$$
\begin{aligned}
k_{\text {in }} C_{p} & =k_{\text {out }} C_{a}, \\
\frac{C_{a}}{C_{p}} & =r \text { (equilibrium ratio) } \\
k_{\text {in }} & =r k_{\text {out }}
\end{aligned}
$$

It therefore,follows that the higher the rate of entry of any compound the lower will be its deficit in the aqueous compared with the plasma-water, when a steadystate has been achieved, until, with rapidly penetrating substances, a rate of entry is attained which equals the rate of exit and the equilibrium ratio becomes unity.

This relationship (equation 2) provided an indirect method of estimating the rate of flow, for the rate of entry and the equilibrium ratio can be determined experimentally without disturbing the hydrodynamics of the eye. When a series of compounds is taken, the minimum value of $k_{\text {out }}$ so obtained will represent the rate of flow, for a constituent of the aqueous cannot leave the anterior chamber at a rate which is lower than the rate of flow. Unfortunately, there are very few reports of dynamic studies on the aqueous humour which state values for both $k_{\text {in }}$ and $r$. To provide further data, these values have therefore been determined for sucrose, a substance of high molecular weight known to enter the anterior chamber slowly (Davson and Duke-Elder, 1948) and was therefore considered likely to leave the anterior chamber only by flow and not by diffusion, and also for glucose in the diabetic animal where utilization would probably be minimal. Table IV (overleaf) summarizes the results of workers who have used this mathematical approach.

\section{EXPerimental Methods}

(1) Determination of the Rate of Entry and Equilibrium Ratio for Sucrose.-Rabbits weighing $2.0-2.2 \mathrm{~kg}$. were used under pentobarbitone sodium anaesthesia. The general method of suddenly raising the blood concentration by the intravenous injection of 5 per cent. sucrose and removing aqueous samples at suitable intervals (20 and $30 \mathrm{~min}$.) follows that used in previous permeability experiments (Ross, 1951a). The equilibrium ratio was determined by plotting the approach of the concentration in the aqueous humour to that in the plasma at 30-min. intervals until the two curves ran parallel; this 
TABLE IV

RATE OF EXIT OF AQUEOUS HUMOUR $\left(k_{\text {out }}\right)$ DERIVED MATHEMATICALLY FROM RATE OF ENTRY INTO ANTERIOR CHAMBER $\left(k_{\text {in }}\right)$ AND EQUILIBRIUM RATIO $(r)$

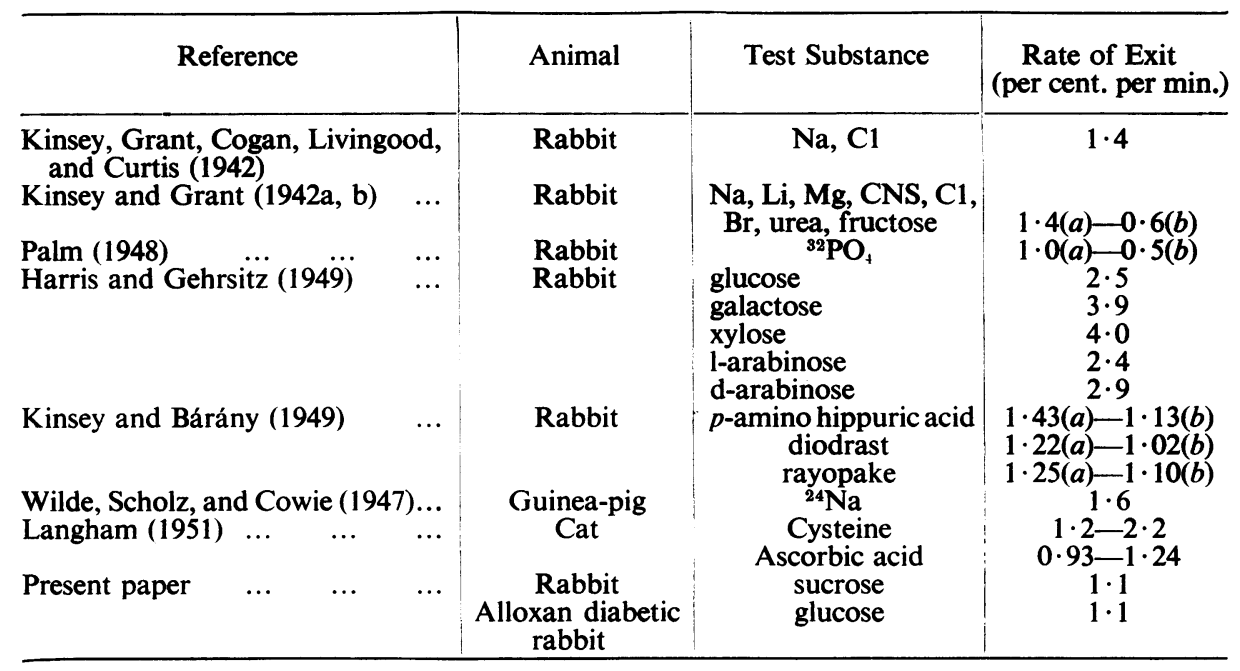

The two values for $k_{\text {flow }}$ given in Col. 4 represent limiting values which result from the method of calculating

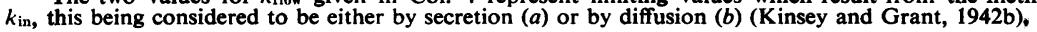

occurred after $5,-6$ hours. The renal vessels were ligated during experiments undertaken to determine the equilibrium value but not in those to determine the rate of entry.

Sucrose was estimated by difference after half of each sample had been hydrolysed with 1.27 $\mathrm{N} \mathrm{H}_{2} \mathrm{SO}_{4}$ and the glucose estimated by the method of Somogyi (1945).

(2) Determination of the Rate of Entry and Equilibrium Ratio for Glucose in the Diabetic Animal.-The experimental procedure is fully described in Ross (1951b). Rabbits weighing $2.0-2.2 \mathrm{~kg}$. were made diabetic by the intravenous injection of alloxan monohydrate, $300 \mathrm{mg}$. $/ \mathrm{kg}$. A week was allowed to elapse after they had become hyperglycaemic before a permeability experiment was performed. The method of determining the rate of entry and the equilibrium ratio was the same as that described for sucrose; pentobarbitone anaesthesia was used and glucose estimated by Somogyi's method.

Results.-The rate of entry of sucrose was found to be $0.23 \times 10^{-2} \mathrm{~min}^{-1}$ and the equilibrium ratio 0.21 . In the case of the alloxan-diabetic rabbit the rate of entry was $1.03 \times 10^{-2} \mathrm{~min}^{-1}$ and the equilibrium ratio 0.92 . These results, together with those of other workers, are presented in the Figure (opposite) as a graph in which $k_{\text {in }}$ is plotted against $r$. The line is drawn through points of minimal rate of exit and therefore represents the rate of flow, giving a value of $1.1 \times 10^{-2} \mathrm{~min}^{-1}$. It will be noted that several points lie above this line; this is compatible with the hypothesis of an aqueous flow, for such compounds are leaving the eye by diffusion as well as by flow.

\section{Discussion}

The fact that all the substances they investigated left the anterior chamber at the same rate led Kinsey and Grant (1942) to postulate that the exit of aqueous humour from the eye is by bulk flow through Schlemm's canal at 


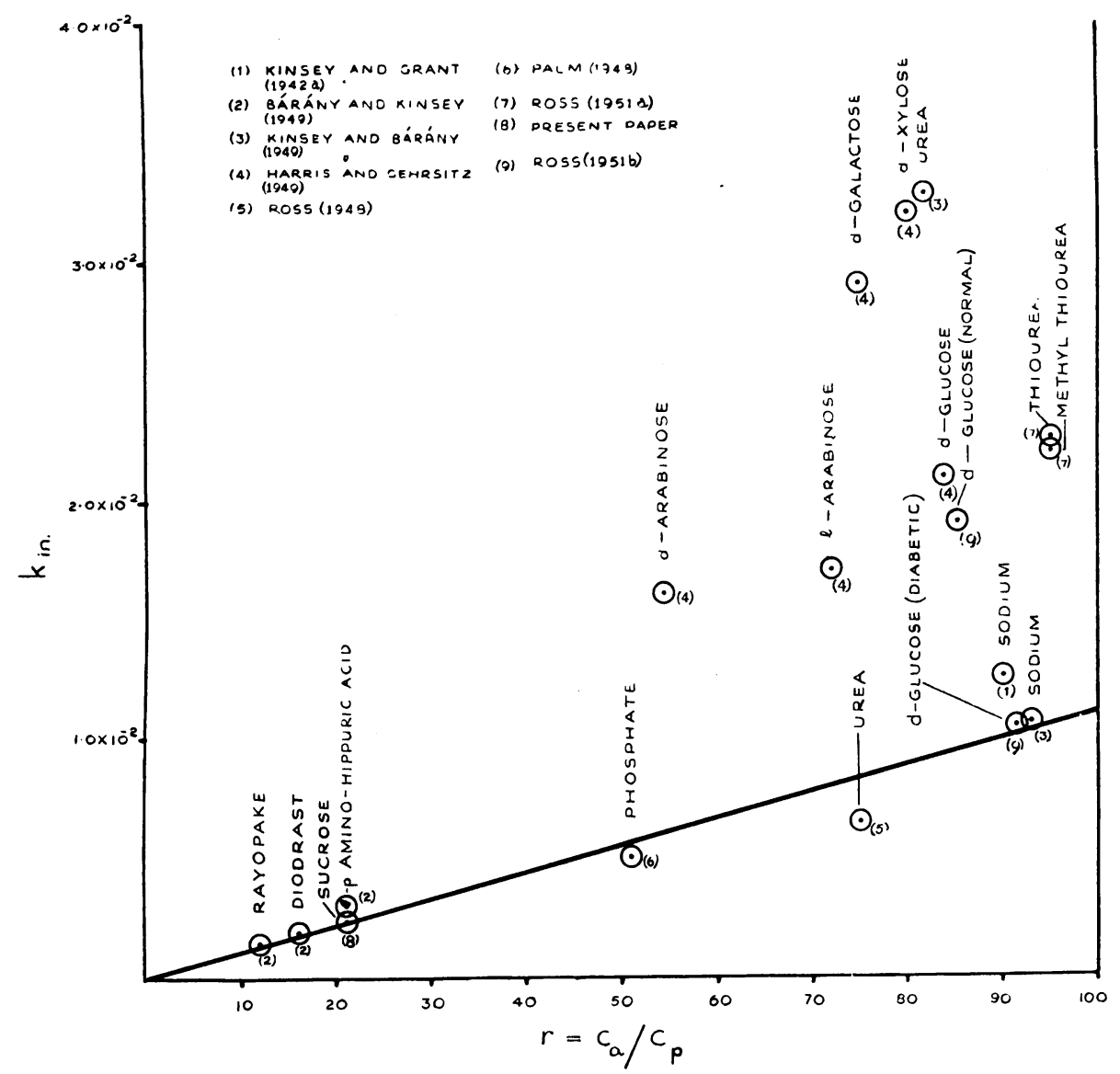

FIGURE.-Relationship between equilibrium ratio $(r)$ and rate of transfer across blood-aqueous barrier $\left(k_{\text {in }}\right)$ in rabbits, from which $k_{\text {out }}$ can be deduced. The line is drawn through the minimum rates of exit $\left(k_{\text {out }}\right)$ and represents a rate of flow $\left(k_{\text {flow }}\right)$ of 1.1 per cent. of the volume of the aqueous humour per minute.

Ordinate: Rate of penetration across blood-aqueous barrier expressed as permeability constant $k_{\text {in }}$

a rate which they calculated to be 1.4 per cent. per min. or $4 \mathrm{cmm}$. of aqueous humour per min. in the rabbit. This hypothesis necessitated the assumption that $4 \mathrm{cmm}$. of aqueous humour are formed per minute to replace that lost, with the result that there must be a continuous circulation of fluid from the site of formation, chiefly in the ciliary body, to its site of exit chiefly by way of Schlemm's canal or its homologue. By the use of heavy water, Kinsey, Grant, and Cogan (1942) determined the rate of accumulation of $\mathrm{D}_{2} \mathrm{O}$ in the anterior chamber and calculated that there was an exchange of about 20 per cent. of the water of the aqueous humour per minute ( $=50 \mathrm{cmm} . / \mathrm{min}$. in the rabbit), part of this exchange being with the blood in the vessels of the iris. It follows that drainage through Schlemm's canal 
is not the only pathway by which the water of the aqueous humour can leave the anterior chamber; there is in addition a diffusional exchange between the aqueous humour and the cornea, the lens, the vitreous cavity, and the vessels of the anterior surface of the iris. The individual contribution of each of these structures to the composition of the aqueous humour has not been studied in detail except in the case of sodium by Maurice (1951). Friedenwald and Pierce (1932b) concluded that the re-absorption of aqueous humour takes place almost exclusively from the anterior chamber, less than 1 per cent. being absorbed by tissues behind the iris; the method they employed, however, interfered with the normal hydrodynamics of the eye. Exchange with the extracellular water of the cornea is rapid, so that the volume of the cornea can be looked upon as an extension of the aqueous humour, increasing the effective volume of the anterior chamber in the rabbit by about 20 per cent. (Maurice). This will introduce an error into the calculated value of $k_{\text {in }}$ in experiments involving a rapid rise in aqueous concentrations as in the glucose and sucrose experiments here described. Exchange with the lens is much slower; Langham and Davson (1949) found that the concentration (activity) of ${ }^{24} \mathrm{Na}$ in the extracellular water of the lens was only 0.6 per cent. of that of the aqueous humour after 24 hours. The vitreous body contributes a little to the fluid flowing through the pupil; Maurice (1951) found that 0.175 per cent. of the sodium in the anterior chamber is derived from the vitreous per minute. Exchange of water, and possibly of some solutes, across the endothelium of the blood vessels of the iris is much more important. In the case of water, the exchange accounts largely for the discrepancy between the $50 \mathrm{cmm}$. which enter the anterior chamber per minute and the $4 \mathrm{cmm}$. which leave it by flow. The permeability of the iris to the solutes of the aqueous is more debatable; for instance, Kinsey and Bárány (1949), on the one hand, state that there is no exchange of sodium across the iris whilst Maurice (1951), on the other hand, gives a figure of 0.65 per cent. of the aqueous concentration of ${ }^{24} \mathrm{Na}$ exchanging across the iris per minute.

Although constituents of the aqueous humour can leave the anterior chamber by pathways other than by drainage, the presence of a continuous flow of aqueous humour demands that they cannot leave at a rate which is slower than the rate of flow. The minimum rate of disappearance shown by any of the constituents of the aqueous humour thus gives an indication of the rate of flow and the Figure shows that this corresponds closely to, and cannot exceed, a rate of 1.1 per cent. per minute in the rabbit. It is interesting to note how close to this figure are the results of some of the early workers in this field who employed methods which are now strongly, and rightly, condemned as unphysiological.

Although a value of $1.1 \times 10^{-2} \mathrm{~min} .^{-1}$ provides the best fit for the minimum value of $k_{\text {out }}\left(=k_{\text {flow }}\right)$ of the various substances plotted in the Figure, it will be noted that urea (Ross) falls below the line and has an uncorrected value 
of $k_{\text {out }}$ of $0.73 \times 10^{-2}$. Maurice (1951) points out that if the correction for urea (to allow for penetration into the cornea, vitreous, etc.) is the same as that for ${ }^{24} \mathrm{Na}$, the corrected value would be $1.1 \times 10^{-2}$, which agrees with Kinsey and Bárány's corrected figure of $1.1 \times 10^{-2} \mathrm{~min}^{-1}$ for Rayopake, Diodrast and $p$-amino-hippuric acid. Many and varied values for the equilibrium ratio and permeability constants of urea have been reported; in rabbits, for instance, Kinsey and Grant (1942a) found an equilibrium ratio of 0.66 and a mean value of $1.4 \times 10^{-2}$ for $k_{\text {out }}$; Kinsey and Robison (1946), using a different chemical technique, reported a value of 0.88 for $r$, and Kinsey (cited by Kinsey and Bárány, 1949) later gives the remarkably high value of $4.0 \times 10^{-2}$ for $k_{\text {out }}$. Kinsey and Bárány have expressed the relationship between $r$ and $k_{\text {out }}$ graphically as a method of deducing the mode of entry into the eye; this method is based on the argument that, if exit was by flow only, entry would have been by secretion only, whereas if exit was by flow plus diffusion, entry would have been by diffusion with or without super-added secretion. The values for urea (Ross), when plotted on this graph, fall on the line indicating entry by secretion alone; this is surprising, since the slow rate of penetration of urea has been shown to be satisfactorily accounted for on the basis of diffusion of a highly lipoidinsoluble non-electrolyte across a lipoid membrane (Ross, 1951a), and the postulation of the participation of a system for the active transport of urea into the eye is therefore unnecessary.

Direct measurements of the rate of flow based on the rate of disappearance of glucose and galactose give mean rates of $1.58 \times 10^{-2} \mathrm{~min}^{-1}$ and $1.03 \times 10^{-2} \mathrm{~min}^{-1}$ respectively. Owing to the extremely rapid clearance of galactose from the blood, consistent figure for $k_{\text {in }}$ and $r$ for this substance could not be obtained in order to compare the rates of flow obtained by the direct and indirect methods. The value of $k_{\text {out }}$ for glucose was found to be $1.52 \times 10^{-2}$ min. $^{-1}$ by the direct method, compared with values per minute of $1.1 \times 10^{-2}$ in the diabetic rabbit and $2.25 \times 10^{-2}$ in the normal rabbit by the indirect method. The higher value in the normal animal can be ascribed to loss by utilization.

The presence of a continuous aqueous flow permits the escape from the anterior chamber of a substance whose concentration in the aqueous humour is below that of the plasma; a transfer in the direction aqueous-to-plasma in such circumstances would of course be impossible by any diffusional process. Hidden away in a review on "The present position of the problem of the intra-ocular fluid and pressure", Duke-Elder and Davson (1948) report experiments by Davson, Duke-Elder, and Maurice, in which inulin (which has a molecular weight of 5,000 and cannot penetrate from the blood into the aqueous humour) was introduced into the anterior chamber by syringe and was found to leave again, even though the inulin concentration of the blood was maintained higher than that of the aqueous throughout the experiment. A similar result was noted in one experiment with galactose 
in which the aqueous humour concentration fell from $64 \mathrm{mg} . / 100 \mathrm{~g}$. to $48 \mathrm{mg} . / 100 \mathrm{~g}$. in 60 minutes during which the plasma concentration was $140 \mathrm{mg} . / 100 \mathrm{~g}$. The demonstration of such a movement against a concentration gradient adds further experimental evidence in favour of the idea of the existence of an aqueous flow.

The various modern experimental methods discussed in this paper all agree in giving a minimum rate of exit, or rate of flow, of 1-2 per cent. per min., and reveal the interesting fact that this is irrespective of the species of animal used: that is, irrespective of the volume of the aqueous humour, which ranges from $1.0 \mathrm{ml}$. in the cat to $0.05 \mathrm{ml}$. in the chicken, and irrespective also of the chemical used as the test substance, and of any anatomical difference in the architecture of the structures draining the anterior chamber. The development of techniques suitable for the clinical determination of the rate of flow of the aqueous humour in man is becoming of importance in the study of glaucoma but cannot be discussed here; reference may be made to the work of Goldmann (1950) and of Grant (1951) in this connection.

\section{SUMMARY}

(1) The experimental evidence in favour of the existence of a continuous circulation of the aqueous through the posterior and anterior chambers of the eye is reviewed.

(2) Previous experimental methods employed to determine the rate of flow of aqueous humour are discussed.

(3) A direct method of estimating the rate of flow without disturbing the hydrodynamics of the eye, by measuring the rate of disappearance of glucose and galactose from the anterior chamber, is described. By this method the rate of flow in rabbits equals 1.58 per cent. per min. of the total volume of the aqueous humour in the case of glucose, and 1.03 per cent. per min. in the case of galactose.

(4) An indirect method of deriving the rate of flow mathematically, from the equilibrium ratio and the rate of transfer of a given substance from the plasma into the aqueous humour, gives a rate of flow of 1.1 per cent. per min., employing sucrose in the normal rabbit and glucose in the diabetic animal.

I am indebted to Sir Stewart Duke-Elder and to Dr. Maurice Langham for a critical discussion of the manuscript of this paper.

\section{REFERENCES}

AsCHER, K. W. (1942). Amer. J. Ophthal., 25, 31, 1174.

AbELSDORFF, G., and WesSely, K. (1909). Arch. Augenheilk. (Ergänzungsheft), 64, 65.

BáránY, E. (1951). Acta physiol. scand., 22, 340.

and KinsEY, V. E. (1949). Amer. J. Ophthal., 32, No. 6 (part 2), 177.

Bellows, J. G., and ChInN, H. (1940). Arch. Ophthal., Chicago, 24, 1144.

BENTZEN, C. F. (1895). v. Graefes Arch. Ophthal., 41, part 4, p. 42.

and LEBER, T. (1895). Ibid., 41, part 3, p. 208.

Bollman, J. L., ManN, F. C., and Power, M. H. (1935). Amer. J. Physiol., 111, 483. 
Davson, H., and Duke-Elder, S. (1948). J. Physiol., 107, 141.

MaUrice, D. M., Ross, E. J., and Woodin, A. M. (1949). I Ibid, 108, 203. and Matchet, P. A. (1951). Ibid., 113, 387.

Duke-Elder, S., and Davson, H. (1948). British Journal of Ophthalmology, 32, 555.

Friedenwald, J. S., and PierCe, H. F. (1932a). Arch. Ophthal., Chicago, 7, 538. (1932b). Ibid., 8, 9.

GifFORD, H. (1886). Arch..Augenheilk., 16, 421.

Goldmann, H. (1946). Ophthalmologica, Basel, 111, 146. (1950). Ibid., 119, 65.

Grant, W. M. (1950a). Arch. Ophthal., Chicago, 44, 204.

(1950b). Cited in Annual Report for 1950 of Howe Laboratory of Ophthalmology, Harvard Medical School.

Harris, J. E., and GeHrsitz, L. B. (1949). Amer. J. Ophthal., 32, No. 6 (part 2), 167.

Henderson, E. E., and Starling, E. H. (1906). Proc. roy. Soc. B., 77, 294.

Hovius, J. (1702). "De circulari humorum ocularium motu". G. van de Water, Traj. ad Rhenum.

(1716). "Troctatus de circulari humorum motu in oculis". Editio nova ... cui accedit epistola apologetica in D. Fredricum Ruyschium. J. Langerak, hugd. Bat.

Jesner, J. (1880). Pflüg. Arch. ges. Physiol., 23, 14.

Kinsey, V. E., and BúránY, E. (1949). Amer.J. Ophthal., 32, No. 6 (part 2), 189. and Grant, W. M. (1942a). J. gen. Physiol., 26, 119. (1942b). Ibid., 26, 131.

- and Cogan, D. G. (1942). Arch. Ophthal., Chicago, 27, 242.

Livingood, J. J., and Curtis, B. R. (1942). Ibid., 27, 1126. and Robison, P. (1946). J. biol. Chem., 162, 325.

Kronfeld, P. C. (1931). Trans. Amer. ophthal. Soc., 29, 164.

KNIES, M. (1878). Arch. Augenheilk., 7, 320.

LANGHAM, M. (1951). British Journal of. Ophthalmology, 35, 409. and Davson, H. (1949). Biochem. J., 44, 467.

LEBER, T. (1895a). Ber. ophthal. Ges. Heidelberg, 24, 83. (1895b). v. Graefes Arch. Ophthal., 41, part 1, p. 235. and PILzeCKer, A. (1906). Ibid., 64, 1 .

Leplat, L. (1889). Ann. Oculist., Paris, 101, 123.

MaURICE, D. M. (1951). "The Permeability of the Cornea", Ph.D. Thesis, University of London.

NiesnamofF, E. (1896). v. Graefes Arch. Ophthal., 42, part 4, p. 1.

PALM, E. (1948). Acta ophthal. Kbh., Suppl. 32.

Ross, E. J. (1949). British Journal of Ophthalmology, 33, 310.

(1951a). J. Physiol., 112, 229.

(1951b). Ibid. In the press.

SeIDel, E. (1921). v. Graefes Arch. Ophthal., 104, 357. (1922). Ibid., 108, 420.

Somogy, M. (1945). J. biol. Chem., 160, 61.

SMITH, Priestley (1888). Ophthal. Rev., 7, 193.

Sugar, H. S. (1942). Arch. Ophthal., Chicago, 28, 315.

UlBRICH, H. (1908). Arch. Augenheilk., 60, 283.

Uribe Y Troncoso, M. (1909). Ann. Oculist., 142, 237.

Wilde, W. S., Scholz, R. O., and Cowie, D. B. (1947). Amer. J. Ophthal., 30, 1516. 